\title{
Pendampingan membuat Soal Berorientasi HOTS bagi Guru-Guru SMK di Pringsewu
}

\author{
Kahfie Nazaruddin, Bambang Riadi*, ling Sunarti, Ali Mustofa, Sarjinah \\ Zamzanah
}

Pendidikan Bahasa dan Sastra Indonesia, Universitas Lampung, Bandar Lampung, 35145, Lampung, Indonesia

\begin{abstract}
Abstrak.
Hasil wawancara dengan guru di SMK YAPEMA Gadingrejo Pringsewu menunjukkan bahwa guru belum memahami dan mampu menyusun soal evaluasi pembelajaran berorientasi HOTS. Guru membutuhkan pendampingan agar mampu menyusun soal tersebut. Atas dasar tersebut pengabdian kepada masyarakat ini dilakukan di SMK YAPEMA Gadingrejo Pringsewu dalam bentuk kegiatan pelatihan. Hasil penilain produk soal yang dibuat peserta diperoleh skor rata-rata sebesar 83,3 dengan kategori A. Hal ini berarti soal yang dibuat oleh peserta dapat digunakan. Dengan demikian, sebagain peserta pelatihan telah mampu membuat soal HOTS dan kegiatan ini berhasil meningkatkan keterampilan peserta dalam membuat soal berorientasi HOTS.
\end{abstract}

Keywords.

Soal, HOTS, Sekolah SMK

\section{PENDAHULUAN}

Perlu penataan penyelenggaraan pendidikan, khususnya kurikulum, sebagai upaya menyiapkan sumber daya manusia yang berkompeten [1-4]. Saat ini kurikulum yang digunakan di Indonesia yaitu kurikulum 2013. Dengan penerapan kurikulum 2013 diharapkan siswa mampu meningkatkan dan mengembankan pengetahuannya secara mandiri dan dapat mengimplementasikan pengetahuannya tersebut dalam kehidupannya [5-7]. Kurikulum 2013 tentu memiliki perbedaan dengan kurikulum sebelumnya karena hasil pengembangan dari kurikulum KTSP, tentu kedua kurikulum tersebut berbeda baik dalam proses pembelajaran di dalam maupun di luar kelas [8].

Pembelajaran dalam kurikulum 2013 menganut dimensi pedagogic modern yakni pendekatan saintifik yang proses pembelajarannya siswa diarahkan untuk membangun konsep baru dan pemecahan masalah [9] berdasarkan fakta yang objektif dan akuntabel [10]. Proses pembelajaran saintifik dikenal dengan singkatan 5M yaitu mengamati, menanya, mengumpulkan data, mengasosiasi, mengomunikasikan. Pembelajaran yang bersifat

\section{* Corresponding author: bambang.riadi@fkip.unila.ac.id}


student center akan mampu mendorong siswa untuk berpikir kritis dan meningkatkan kemampuan berpikir tingkat tinggi siswa.

Salah satu aspek yang berkaitan dengan pembelajaran saintifik adalah evaluasi pembelajaranya pun harus melatih siswa menggunakan penalarannya. Oleh karena itu, guru dituntut mampu membuat soal berorientasi Higher Order Thinking Skils (HOTS), yaitu soal yang pertanyaannya mampu melatih siswa berpikir tingkat tinggi pada level analisis, evaluasi, dan mencipta [11]. Namun untuk menyusun soal HOTS masih banyak guru yang belum mampu membuatnya. Hal ini dapat disebabkan oleh guru yang cenderung menggunakan soal dari buku penunjang yang didominasi oleh pertanyaan-pertanyaan pada level Low Order Thinking Skills (LOTS) yakni mengingat, memahami dan menerapkan [12].

Pemberian soal HOTS bertujuan untuk menciptakan pembelajaran yang menantang bagi siswa untuk berefleksi dan menerapkan penalarannya [7,13]. Dalam melakukan evaluasi khususnya evaluasi pada aspek kognitif, seorang guru dituntut untuk dapat mengembangkan berbagai instrumen evaluasi yang tepat dan mampu menunjukkan kemampuan siswa secara komprehensif [14]. Kenyataannya, kualitas soal yang dihasilkan guru relatif belum teruji kebenarannya, sehingga soal yang digunakan sewaktu-waktu dalam ulangan atau ujian hampir selalu sama. Perkembangan cara berpikir siswa seharusnya diikuti oleh perkembangan guru dalam menysusun soal yang berada pada level aplikasi dan penalaran [7]. Soal HOTS seyogyanya digunakan agar siswa terbiasa dengan soal-soal yang menantang kemampuan berpikirnya. Namun pada kenyataannya masih banyak guru yang belum memahami atau menguasai cara menyusun dan mengembangkan soal-soal HOTS seperti yang direkomendasikan dalam kurikulum 2013.

Berdasarkan hasil wawancara dengan guru dan Kepala SMK Yapema Pringsewu diperoleh kesimpulan bahwa guru-guru umumnya masih kesulitan dalam menyusun dan mengembangkan soal berorientasi HOTS. Kemampuan guru dalam menyusun soal HOTS dapat digolongkan masih lemah yang disebabkan oleh guru belum memahami cara pembuatan dan pengembangan soal HOTS, pelatihan terkait pengembangan soal HOTS masih minim, dan guru belum memandang penting soal HOTS bagi siswa.

Berdasarkan permasalahan tersebut, maka guru perlu disiapkan mampu menyusun soal HOTS untuk mengembangkan ketrampilan berpikir kritis siswa. Oleh karena itu, penting untuk dilaksanakan pendampingan penyusunan soal HOTS untuk meningkatkan kompetensi guru.

\section{METODE}

Metode yang digunakan dalam pengabdian ini adalah dengan mengungkap masalah terkait penyusunan soal beerbasis HOTS di SMK YAPEMA Gadingrejo Pringsewu, selanjutnya dilakukan diskusi dengan mitra terkait pelatihan yang dibutuhkan guru. Tim pengabdian dan sekolah menyepakati kegiatan pelatihan dengan mengusung tema "Peningkatan Kompetensi Pedagogik Tenaga Pendidik Melalui Pendampingan Penyusunan Soal Higher Order Thingking Skills (HOTS) bagi Guru-Guru di SMK Yapema Gadingrejo Pringsewu" dan dilaksanakan di Aula SMK YAPEMA pada tanggal 20 Agustus 2021 dengan jumlah peserta 20 orang guru.

Kegiatan pelatihan menggunakan strategi ceramah, diskusi, dan praktik pembuatan soal. Ceramah digunakan untuk menyampaikan materi pelatihan, diskusi digunakan untuk menggali pemahaman peserta pelatihan, dan praktik digunakan untuk melatih keterampilan guru dalam penyusunan soal berbasis HOTS. 


\section{HASIL DAN PEMBAHASAN}

\section{Gambaran Proses Pelatihan}

Peserta pelatihan adalah guru-guru SMK YAPEMA Gadingrejo Pringsewu dari berbagai guru mata pelajaran yang berjumlah 22 orang. Pelatihan dilaksanakan pada tanggal 20 Agustus 2021 mulai pukul 08.00 -15.30 WIB.

Pelatihan diawali dengan pembukaan oleh Kepala SMK YAPEMA GAdingrejo Pringsewu. Kepala sekolah menyambut baik kegiatan ini dan berharap peserta dapat mengikutinya dengan baik. Selanjutnya, tim pengabdian secara bergantian menyampaikan materi pelatihan dan tampak peserta memperhatikan dengan seksama. Setela itu, terjadi diskusi yang hangat antara peserta dan tim pengabdian. Peserta umumnya merasa sulit membuat soal berbasis HOTS karena mereka tidak paham bagaimana kriteria soal HOTS tersebut.

Saat praktik penyusunan soal, peserta secara berkelompok sesuai mata pelajaran yang diampu melakukan analisis kompetensi dasar sampai penbuatan soalnya. Tim pengabdian secara rutin mengontrol jalannya praktik dan membantu peserta yang mengalami kesulitan. Diakhir kegiatan, peserta secara bergiliran mempresentasikan hasil kerjanya di depan kelas untuk memperoleh tanggapan dari peserta lain dan tim pengabdian. Dokumentasi pelaksanaan kegiatan dapat dilihat pada gambar di bawah ini.

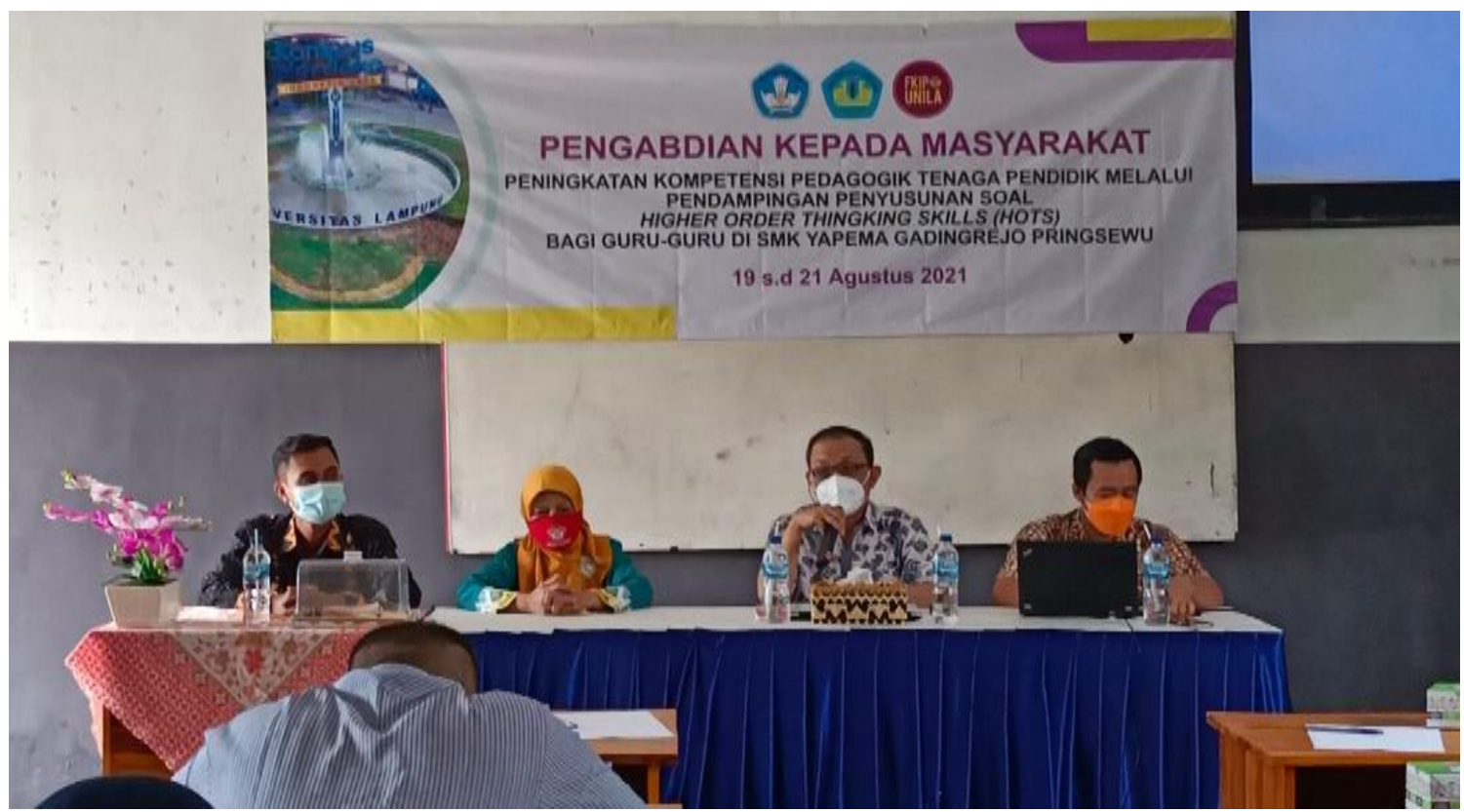

Gambar 1. Kepala sekolah dan tim pengabdian membuka kegiatan 


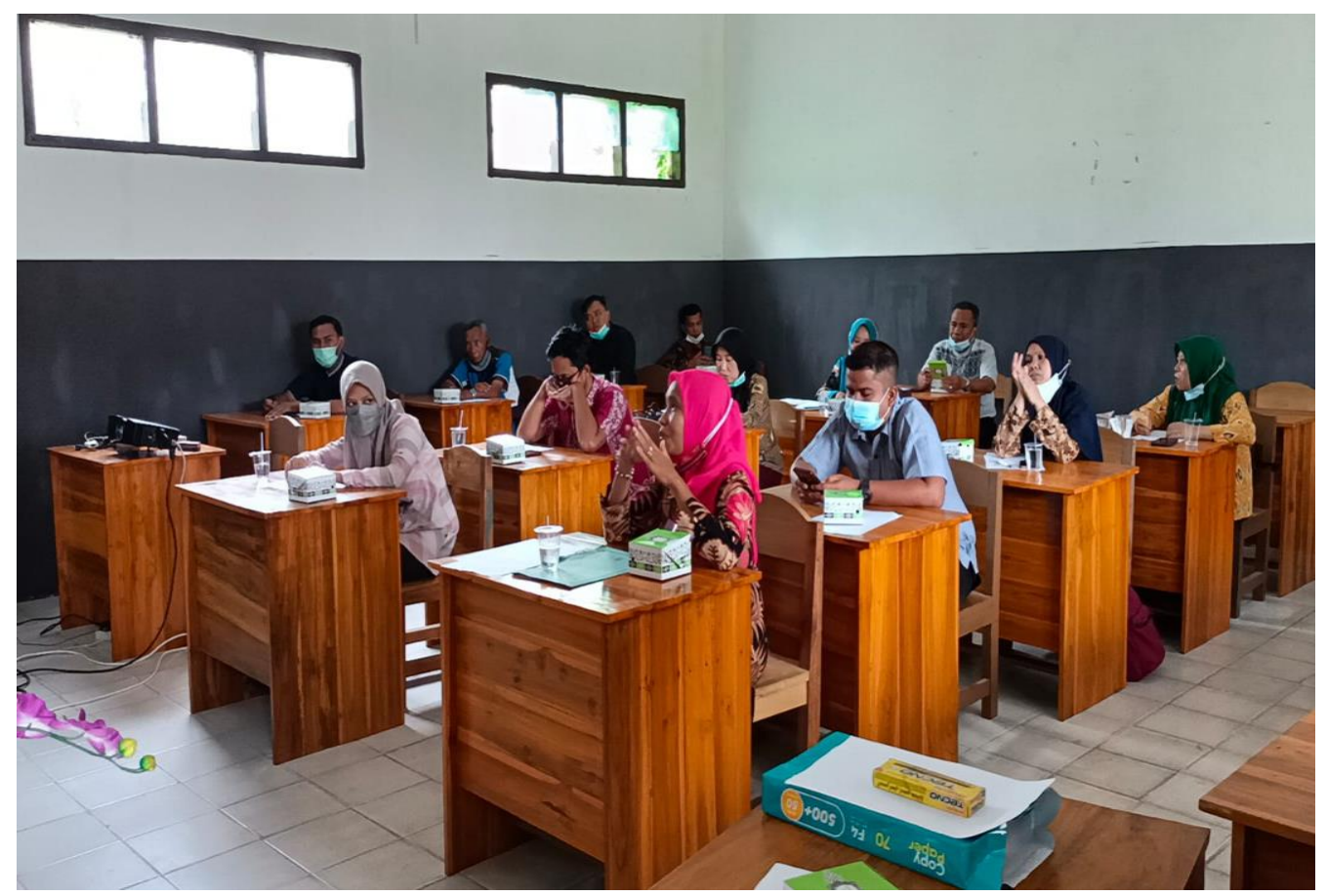

Gambar 2. Diskusi peserta dan tim pengabdian

\section{Kemampuan Peserta dalam Penyusunan Soal Berbasis HOTS}

Hasil penilaian tim pengabdian terhadap produk soal yang dibuat oleh peserta dapat dilihat pada tabel di bawah ini.

Tabel 1. Kemampuan Penyusunan Soal Peserta Pelatihan

\begin{tabular}{|c|c|c|c|c|}
\hline Nilai & $\mathbf{F}$ & $\%$ & Predikat & Keterangan \\
\hline $\begin{array}{c}N<70 \\
71 \leq N \leq 80\end{array}$ & $\begin{array}{l}0 \\
9\end{array}$ & $\begin{array}{l}0 \\
41\end{array}$ & $\begin{array}{l}\mathrm{C} \\
\mathrm{B}\end{array}$ & $\begin{array}{l}\text { Masih perlu dibina } \\
\text { Sudah dapat digunakan } \\
\text { sebagai contoh untuk guru } \\
\text { lain dengan perbaikan } \\
\text { dibagian tertentu }\end{array}$ \\
\hline$N>80$ & 13 & 59 & A & $\begin{array}{l}\text { Dapat menjadi contoh untuk } \\
\text { guru lain }\end{array}$ \\
\hline Jumlah & 22 & 100 & & \\
\hline Rata-Rata & & & A & $\begin{array}{l}\text { Dapat menjadi contoh untuk } \\
\text { guru lain }\end{array}$ \\
\hline
\end{tabular}

Tabel di atas menunjukkan bahwa sebagian besar peserta telah mampu membuat soal yang berorientasi HOTS dengan nilai rata-rata 83,3 dengan predikat A. Terdapat 13 peserta memperoleh nilai diatas 80 yang berarti soal yang dibuat dapat digunakan dan menjadi contoh bagi guru lainnya. Namun masih ada 9 peserta yang harus memperbaiki soalnya pada bagian tertentu seperti kalimat dan gambar.

Berdasarkan skor yang diperoleh peserta, terlihat bahwa guru memiliki kemampuan menyusun soal. Peserta pelatihan telah mampu menyusun soal yang berbasis HOTS. Peserta mampu menurunkan KD menjadi IPK yang berada pada level HOTS kemudian menyusun soal dengan level sesuai IPK yang telah dirumuskan

Peserta pelatihan mengungkapkan bahwa kesulitan dalam penyusunan soal berorientasi HOTS ketika menyusun stimulus soal dalam bentuk cerita. Memang dibutuh kreativitas guru dalam menghasilkan variasi dan kualitas stimulus [15], serta menarik dan kontekstual [16]. Namun, setelah mengikuti pelatihan peserta telah mampu membuat stimulus dengan baik. Pelatihan yang dilakukan oleh tim pengabdian Unila telah mampu mengubah pemahaman 
dan keterampilan guru dalam membuat soal berorientasi HOTS lebih baik. Hal ini menunjukkan bahwa pelatihan ini mampu mengasah keterampilan peserta dalam menyusun soal HOTS untuk mengevaluasi pembelajaran.

\section{KESIMPULAN}

Pengabdian kepada masyarakat dilakukan oleh tim FKIP Unila dalam rangka untuk memecahkan masalah rendahnya pemahaman dan keterampilan guru terhadap penyususnan soal berorientasi HOTS. Padahal soal tipe ini digunakan untuk mengembangkan kemampuan berpikir kritis dan kreatif siswa. Dimana keterampilan ini harus dikembangkan dalam pembelajaran abad 21. Kemudaian tim pengabdian memnyusun sebuah kegiatan dalam bentuk pelatihan yang bekerjasama dengan SMK YAPEMA Gadingrejo Pringsewu. Berdasarkan hasil penilaian saat penyusunan soal HOTS diperoleh skor rata-rata sebesar 83,3 dengan kategori A. Hal ini berarti soal yang dibuat oleh peserta dapat digunakan. Dengan demikian, peserta pelatihan telah mampu menyusun soal HOTS.

\section{UCAPAN TERIMA KASIH}

Kami mengucapakan terima kasih kepada LPPM Universitas Lampung yang telah mendanai kegiatan pelatihan ini. Tidak lupa kami juga mengucapkan terimakasih atas kerjasamanya kepada Kepala Sekolah dan guru SMK YAPEMA Gadingrejo Pringsewu.

\section{DAFTAR PUSTAKA}

[1] Hunter, B., White, G. P., \& Godbey, G. C. (2006). What does it mean to be globally competent? Journal of Studies in International Education, 10(3), 267-285.

[2] Machali, I. (2014). Kebijakan perubahan kurikulum 2013 dalam menyongsong Indonesia emas tahun 2045. Jurnal Pendidikan Islam, 3(1), 71-94.

[3] Wahab, R., \& others. (2012). Reformulasi Inovasi Kurikulum: Kajian Life Skill Untuk Mengantarkan Peserta Didik Menjadi Warga Negara Yang Sukses. Ta'dib: Jurnal Pendidikan Islam, 17(02), 217-254.

[4] Woolley, T., Clithero-Eridon, A., Elsanousi, S., \& Othman, A.-B. (2019). Does a socially-accountable curriculum transform health professional students into competent, work-ready graduates? A crosssectional study of three medical schools across three countries. Medical Teacher, 41(12), 1427-1433.

[5] Aji, W. N., \& Budiyono, S. (2018). The teaching strategy of Bahasa Indonesia in curriculum 2013. International Journal of Active Learning, 3(2), 58-64.

[6] Hasan, S. H. (2013). History education in curriculum 2013: A new approach to teaching history. Historia: Jurnal Pendidik Dan Peneliti Sejarah, 14(1), 163-178.

[7] Sofyan, F. A. (2019). Implementasi HOTS pada kurikulum 2013. INVENTA: Jurnal Pendidikan Guru Sekolah Dasar, 3(1), 1-9.

[8] Zaini, H. (2015). Karakteristik kurikulum 2013 dan kurikulum tingkat satuan pendidikan (KTSP). El-ldare: Jurnal Manajemen Pendidikan Islam, 1(01), 15-31.

[9] Kurniaman, O., \& Noviana, E. (2017). Penerapan Kurikulum 2013 dalam meningkatkan keterampilan, sikap, dan pengetahuan. Primary: Jurnal Pendidikan Guru Sekolah Dasar, 6(2), 389-396.

[10] Leksono, J. W. (2015). Pendekatan Saintifik pada Kurikulum 2013 untuk Meningkatkan Keterampilan Berpikir Kritis Siswa. Proceedingfptk, 437.

[11] Wahyuningtyas, N., \& Ratnawati, N. (2018). WORKSHOP PENGEMBANGAN SOAL HIGHER ORDER THINKING SKILL (HOTS) BAGI GURU-GURU MGMP IPS KABUPATEN MALANG PELATIHAN PENYUSUNAN. Jurnal Praksis Dan Dedikasi Sosial (JPDS), 73-79. 
[12] Ayuningtyas, N. (2013). Proses penyelesaian soal higher order thinking materi aljabar siswa SMP ditinjau berdasarkan kemampuan matematika siswa. MATHEdunesa, 2(2).

[13] Lestari, A., Saepulrohman, A., \& Hamdu, G. (2016). Pengembangan soal tes berbasis hots pada model pembelajaran latihan penelitian di sekolah dasar. PEDADIDAKTIKA: Jurnal Ilmiah Pendidikan Guru Sekolah Dasar, 3(1), 74-83.

[14] Kristanto, P. D., \& Setiawan, P. G. F. (2020). Pengembangan Soal HOTS (Higher Order Thinking Skills) Terkait Dengan Konteks Pedesaan. PRISMA, Prosiding Seminar Nasional Matematika, 3, 370-376.

[15] Kristanto, P. D., \& Setiawan, P. G. F. (2020). Pengembangan Soal HOTS (Higher Order Thinking Skills) Terkait Dengan Konteks Pedesaan. PRISMA, Prosiding Seminar Nasional Matematika, 3, 370-376.

[16] Fanani, M. Z. (2018). Strategi pengembangan soal hots pada kurikulum 2013. Edudeena: Journal of Islamic Religious Education, 2(1). 